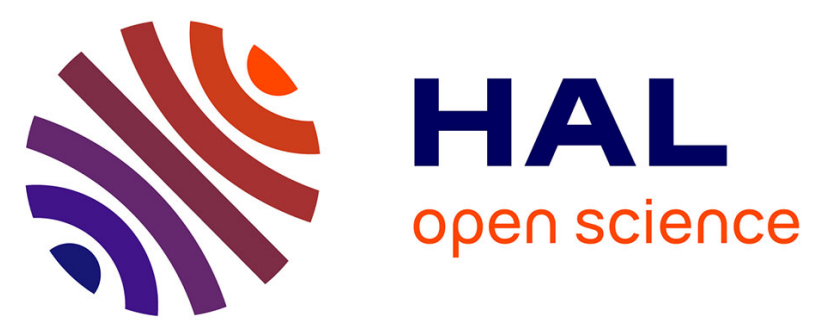

\title{
An Innovative Method for 3-D Shape, Strain and Temperature Full-Field Measurement Using a Single Type of Camera: Principle and Preliminary Results
}

Jean-José Orteu, Y Rotrou, Thierry Sentenac, Laurent Robert

\section{- To cite this version:}

Jean-José Orteu, Y Rotrou, Thierry Sentenac, Laurent Robert. An Innovative Method for 3-D Shape, Strain and Temperature Full-Field Measurement Using a Single Type of Camera: Principle and Preliminary Results. Experimental Mechanics, 2008, 48 (2), p.163-179. 10.1007/s11340-007-9071-7 . hal-01170373

\section{HAL Id: hal-01170373 \\ https://imt-mines-albi.hal.science/hal-01170373}

Submitted on 1 Jul 2015

HAL is a multi-disciplinary open access archive for the deposit and dissemination of scientific research documents, whether they are published or not. The documents may come from teaching and research institutions in France or abroad, or from public or private research centers.
L'archive ouverte pluridisciplinaire HAL, est destinée au dépôt et à la diffusion de documents scientifiques de niveau recherche, publiés ou non, émanant des établissements d'enseignement et de recherche français ou étrangers, des laboratoires publics ou privés. 


\title{
An Innovative Method for 3-D Shape, Strain and Temperature Full-Field Measurement using a Single Type of Camera: Principle and Preliminary Results
}

\author{
Jean-José Orteu* , Yann Rotrou, Thierry Sentenac, \\ Laurent Robert \\ École des Mines d'Albi-Carmaux, Campus Jarlard, 81013 Albi, France
}

\begin{abstract}
An innovative technique for measuring both the shape, the displacement, the strain and the temperature fields at the surface of an object using a single stereovision sensor is proposed. The sensor is based on two off-the-shelf low-cost high-resolution uncooled CCD cameras. To allow both dimensional and thermal measurements, the sensor operates in the visible and near infrared (NIR) spectral band (0.7-1.1 $\mu \mathrm{m})$, and a radiometric and geometric calibration of the sensor is required. This technique leads to a low-cost camera-based simplified instrumentation that gives simultaneously dimensional/kinematical and thermal field measurements.
\end{abstract}

Key words: geometric camera calibration, radiometric camera calibration, shape measurements, strain measurements, temperature measurements, full-field measurements, stereovision, digital image correlation (DIC), stereo-correlation, 3-D metrology, experimental mechanics. 


\section{Introduction}

In experimental mechanics it can be necessary to know the strains and the temperature of the specimen under study. This concerns all mechanical tests at high temperature (for instance fatigue studies [1,2], thermomechanical behaviour of refractory concretes $[3,4])$ and the study of processes involving deformations at high temperature (for instance welding [5], glass forming [6], super plastic forming [7,8], heat treatment [9], etc.). For strain measurements, many sensors are available, from the classical strain gages up to more sophisticated non-contact optical sensors providing full-field measurements [10-13]. For temperature measurements, many sensors are also available, from the classical thermocouples up to more sophisticated non-contact sensors like infrared cameras or pyrometers $[14,15]$. Thus, getting the strains and temperature at the same time implies generally a multi-instrumentation of the set-up and it is not so easy to combine the measurements of various categories in order to get the strains and the temperature at a given point of the specimen surface.

Some authors have already proposed to integrate thermographic data and/or 3-D shape data and/or kinematical data. Bruck et al. [5] proposed the VITA system based on high-speed thermal imaging and stereoscopic video imaging to measure temperature and 3-D deformation fields on the surface of specimens during the Gas Metal Arc Welding process. Their technique requires three cameras: an IR camera and two CCD cameras for the stereovision sensor. Some new developments have been proposed very recently. Colantonio et al. [16] propose a technique to combine the thermal data provided by a

\footnotetext{
* Corresponding author.

Email address: Jean-Jose.Orteu@enstimac.fr (Jean-José Orteu).
} 
classical thermocamera with the 3-D shape data provided by a stereovision sensor. Their technique requires three cameras (an IR camera and two CCD cameras for the stereovision sensor) and a specific calibration procedure is needed to perform the fusion of the thermal and kinematical data provided by two different types of cameras. Satzger et al. [17] propose to utilize an infrared camera with a fringe projection technique to obtain a cloud of 3-D points and to map thermographic images onto the specimen shape. They use a classical thermographic camera and as they are using a fringe projection technique they can obtain the shape of the specimen but they cannot measure its surface deformation. Moreover the measured specimen needs to be placed into a socalled navigation cage in order to fit point clouds taken from different points of view, which somewhat complicates the experimental setup. Wattrisse et al. [18] propose to combine Digital Image Correlation (DIC) with infrared thermography in order to get the 2-D displacement/strain and temperature fields of a planar specimen. In their work, the authors utilize two different types of cameras: a visible CCD camera for displacement and strain measurements and an IR Focal Plane Array (FPA) camera for temperature measurements, and they face the problem of fusing data provided by two different sensors. Moreover, as they are using a single CCD camera, they can measure the 2-D surface displacement/strain field of a planar specimen undergoing an in-plane deformation but they cannot obtain the 3-D surface displacement/strain field of any 3-D object subjected to any thermo-mechanical loading.

In this paper, an innovative technique for measuring both the shape, the displacement, the strain and the temperature fields of an object using a single type of camera is proposed. The sensor is based on two off-the-shelf lowcost high-resolution uncooled Charge-Coupled-Device (CCD) cameras. Ther- 
mal measurements using this kind of camera is made possible thanks to our recent developments in the field of temperature measurements using CCD cameras [19-22]. These developments have permitted to measure temperatures higher than $300{ }^{\circ} \mathrm{C}$ with $\mathrm{CCD}$ cameras operating in the visible and near infrared (NIR) spectral band $(0.7-1.1 \mu \mathrm{m})$. Our proposed method utilizes a stereovision sensor that can provide at the same time the shape, the displacement, the strain and the temperature fields of the specimen. This technique leads to a low-cost camera-based simplified instrumentation that gives simultaneously dimensional/kinematical and thermal field measurements.

Due to the metrological aspect of our work, an accurate radiometric and geometric calibration of the sensor is required. These calibration steps are performed before the sensor can be used for dimensional and thermal measurements.

The radiometric calibration is performed to compute the radiometric model parameters of the camera that relate the temperature of an ideal blackbody source to the output of the camera (pixel gray levels). The radiometric model parameters are used to transform an image into a thermal map.

The geometric calibration of the stereovision sensor is a preliminary step required to determine its geometric parameters: the intrinsic parameters of each camera and the relative position and orientation of the two cameras. These calibration data are required to compute by triangulation the $3-\mathrm{D}$ coordinates of a point corresponding to matched pixels in the two stereo images.

After the radiometric and geometric calibration, the sensor is ready for measurement. 
The shape or the 3-D displacement/strain field of the specimen are obtained using a stereo-correlation technique. The temperature field is obtained by processing one of the two images provided by the stereovision sensor. Using the radiometric model, an apparent blackbody temperature map can be computed from the pixel intensities.

In static situations (no deformation), a stereo pair of images of the specimen under study is acquired. By processing the images, the 3-D shape of the specimen and also the temperature of each point of its surface are obtained. Thus, a thermal map $(X, Y, Z, T(X, Y, Z))$ can be displayed onto the 3 -D shape.

In non-static situations, a sequence of time-varying pairs of stereo images of the specimen undergoing deformation is acquired. By processing the images, the $3-\mathrm{D}$ shape of the specimen at each acquisition time, and also the strain and the temperature at each point of its surface are obtained. Thus, a strain map $\left(X, Y, Z, \varepsilon_{x x}(X, Y, Z), \varepsilon_{y y}(X, Y, Z), \varepsilon_{x y}(X, Y, Z)\right)$ or a thermal map $(X, Y, Z, T(X, Y, Z))$ can be displayed onto the 3 -D shape.

It should be noted that the method presented in this paper utilizes two CCD cameras (stereovision) in order to provide simultaneously the shape, the 3-D displacement/strain and temperature fields. Of course, if one is not interested in the shape and is dealing with a 2-D problem (for instance the 2-D deformation of a planar specimen) the same methodology could be used with a single CCD camera to get simultaneously the 2-D displacement/strain and temperature fields (simplified instrumentation).

The paper is organized as follows. In sections 2 and 3 the radiometric and geometric calibration steps are presented. In section 4 the experimental setup used for our work is presented. In sections 5 and 6 the methodology to obtain 
simultaneously the shape, the displacement, the strain and the temperature field is presented along with some experimental results. A discussion of the results is given in section 7 .

\section{Radiometric calibration}

From a radiometric point of view, a camera is a set of radiometers (each pixel is a radiometer) that converts an incident flux to a set of pixel gray level values (see Figure 1).

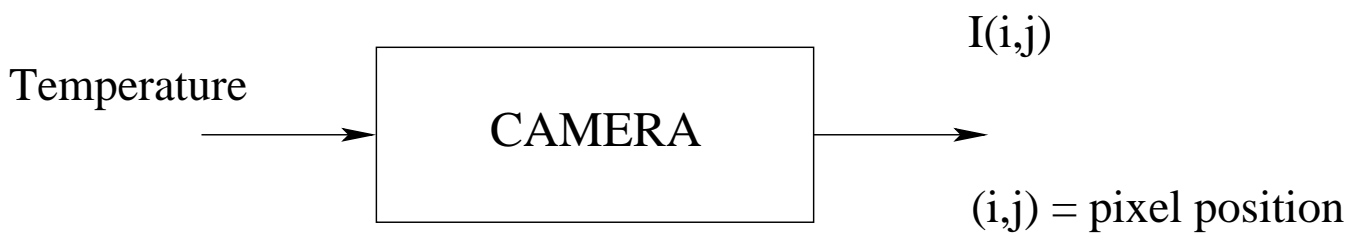

Fig. 1. From a radiometric point of view, a camera converts a temperature to a pixel gray level value $I(i, j)$.

The incident flux is related to the apparent temperature (the temperature of a blackbody source emitting the same flux) by using the Planck's law.

The radiometric model describes the relation between the apparent temperature and the signal $I(i, j)$ acquired by the camera (pixel gray levels) and allows a thermal map to be computed from an image acquired by the camera. The radiometric model parameters are computed using a radiometric calibration procedure.

"Traditional" radiometric models are designed for infrared cameras with a single photodetector with a linear photoresponse and operating in short (3$5 \mu \mathrm{m})$ and long $(8-12 \mu \mathrm{m})$ wavelengths. 
In our work, off-the-shelf uncooled CCD cameras are utilized. These cameras include an array of photodetectors. For a given camera, the response of each photodetector is not necessary identical and the signal output of each pixel is not necessary independant. This needs to be corrected in order that each pixel could be considered as independent and identical with a linear response versus the incident flux (see section 2.1). Moreover, these cameras operate in the near infrared spectral band $(0.7-1.1 \mu \mathrm{m})$ which requires to introduce a specific radiometric model (see section 2.2).

\subsection{CCD camera corrections}

Before the calibration step, images are corrected as illustrated in figure 2.

First, CCD cameras do not feature a strictly linear photoresponse. As an example, a typical non-linearity of $7 \%$ has been observed, which can cause an error of $10{ }^{\circ} \mathrm{C}$ at $1000{ }^{\circ} \mathrm{C}$ [20]. In order to obtain a better temperature measurement accuracy, the non linearity of the detector photoresponse needs to be corrected. After this correction, a linear relation between the incident flux and the camera output signal is assumed.

Next, as a CCD camera is a multi-detector array, non uniformities between detectors have to be checked [23-26] and to be corrected if required. With CCD cameras a difference of uniformity less than $0.5 \%$ has been observed, but with CMOS cameras ${ }^{1}$ a photoresponse non uniformity up to $20 \%$ has been observed, which can cause an error up to $25{ }^{\circ} \mathrm{C}$ at $1000{ }^{\circ} \mathrm{C}$.

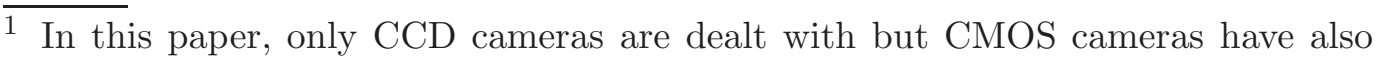
been investigated [21,22]. 


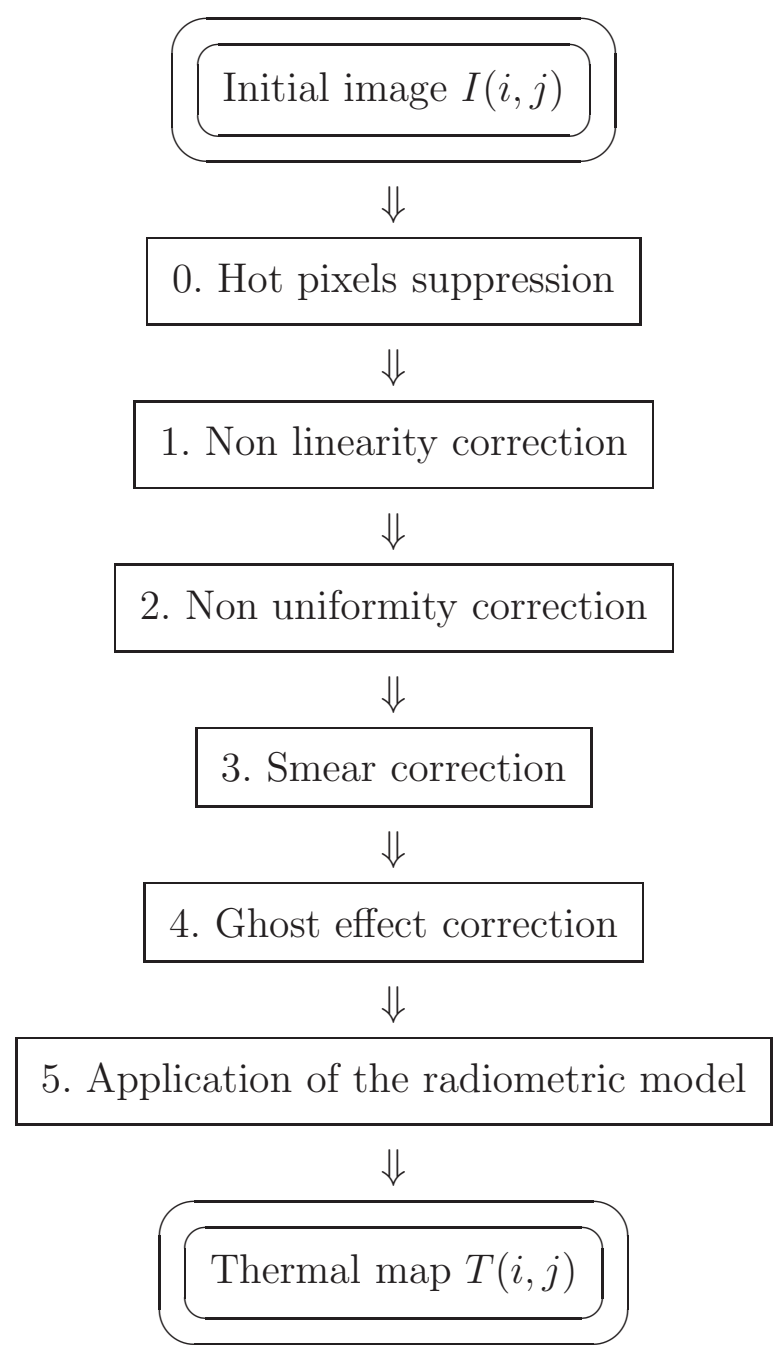

Fig. 2. Summary of the CCD camera corrections for thermal measurements.

If the non linearity and non uniformity are not corrected, this can affect the difference of temperature between two adjacent points, which can be a serious problem to compute thermal gradients [22].

Some phenomena can make the output signal of two or more pixels of the detector array being cross-correlated: the blooming, the smearing, the optical reflections and the diffusion of the generated charges in the substrate of the detector [27]. Blooming can be tackled by adapting the integration time to 
avoid saturation. Smearing can be corrected for some specific CCD cameras [28,29]. Optical reflections can be corrected also if required [22].

Finally, after the corrections, we end up with linear, identical and independent pixels and only one radiometric model applies for all pixels.

\subsection{Specific radiometric model}

In the NIR spectral range used in our work, a specific radiometric model is required. Indeed, in this spectral range, the luminance increases faster with the temperature than in the infrared spectral range. In the NIR spectral range $(1 \mu \mathrm{m})$ the ratio of the spectral luminances between 300 and $1000{ }^{\circ} \mathrm{C}$ is about one million, whereas in the Long-Wave Infrared (LWIR) spectral range $(10 \mu \mathrm{m})$ the ratio is only five.

To measure such different luminances, the camera parameters have to be controlled in-line and particularly the integration time, which corresponds to the length of time that the sensor is exposed (that photons are collected). In order to cope with the large range of luminances, many integration times have to be used, typically 1000 integration times between $100 \mu$ s and 10 s. Usually, the radiometric model parameters need to be computed for each integration time which is long and costly. In order to avoid performing too many calibrations, some authors have proposed to find the parameters for some integration times from the parameters already available for other integration times but this leads to important thermal errors [30]. The specific radiometric model used in our work has been designed in order that a single set of parameters can be used for all integration times. 
Moreover, in the NIR spectral band, the spectral density of energy moves to lower wavelengths when the temperature increases which requires the introduction of an extended effective wavelength $\lambda_{x}(T)$ into the radiometric model. The extended effective wavelength decreases with the temperature. It is linked to the spectral efficiency of the detector [31].

To sum up, the specificity of the proposed radiometric model is the introduction of an effective wavelength which depends on the temperature, and also the fact that a single model is used for all integration times.

The specific radiometric model that we have developed for silicon FPA cameras is given by equations (1) and (2).

$$
I_{n}(T)=\frac{I}{t_{i}}(T)=k_{w} \exp \left(\frac{-C_{2}}{\lambda_{x}(T) T}\right)
$$

with:

$$
\frac{1}{\lambda_{x}(T)}=a_{0}+\frac{a_{1}}{T}+\frac{a_{2}}{T^{2}}
$$

where $I$ is the pixel gray level value registered by the camera, $t_{i}$ is the integration time of the camera and $T$ the temperature. $C_{2}$ is the second Planck's constant $\left(1.44 \times 10^{-2} \mathrm{~m} . \mathrm{K}\right) . I_{n}$ is the pixel gray level value normalized by the integration time.

This model depends on 4 parameters $\left(k_{w}, a_{0}, a_{1}, a_{2}\right)$ that are determined during the radiometric calibration process.

It should be noted that for a temperature range of $300-700{ }^{\circ} \mathrm{C}$, the use of a 
linear expression (first order with 3 parameters: $k_{w}, a_{0}$ and $a_{1}$ ) of effective extended wavelength is sufficient. A second order expression has to be used for a temperature range from 300 to $1000{ }^{\circ} \mathrm{C}$. In that case, 4 parameters need to be determined during the calibration process.

The identification of the model parameters requires some known reference temperatures. These reference temperatures are provided by a blackbody cavity. Figure 3 shows the calibration setup with the blackbody cavity (a LANDCAL P1200B) and the camera aligned with the blackbody cavity using a Newport translation stage.

During the calibration procedure, the parameters of the radiometric model $I_{n}(T)$ are computed from known temperatures of the reference blackbody and corresponding corrected pixel intensities (see section 2.1), for a normalized integration time of $1 \mathrm{~s}$. A typical calibration curve is shown on Figure 4. The originality of the approach is the computation of a single set of parameters for all integration times being considered. Instead of dealing with a calibration curve $I(T)$ for each integration time $t_{i}$ (classical approach), a single calibration curve $I_{n}(T)=\frac{I}{t_{i}}(T)$ is used.

Additionally, it should be noted that an efficient identification procedure has been proposed [22]. Only three measurements at high temperatures are needed to find the model parameters. For the $400-700{ }^{\circ} \mathrm{C}$ temperature range, the parameters are: $k_{w}=2.12 \times 10^{11}$ gray level ; $a_{0}=1.1 \times 10^{6} \mathrm{~m}^{-1}$ and $a_{1}=$ $-3.02 \times 10^{7} \mathrm{~K} / \mathrm{m}$.

Due to the camera technology used in the present work (uncooled CCD cameras in the NIR spectral band) only temperatures higher than $300{ }^{\circ} \mathrm{C}$ can be measured $[20,21,32,33]$. Nevertheless, the proposed technique can be useful for 


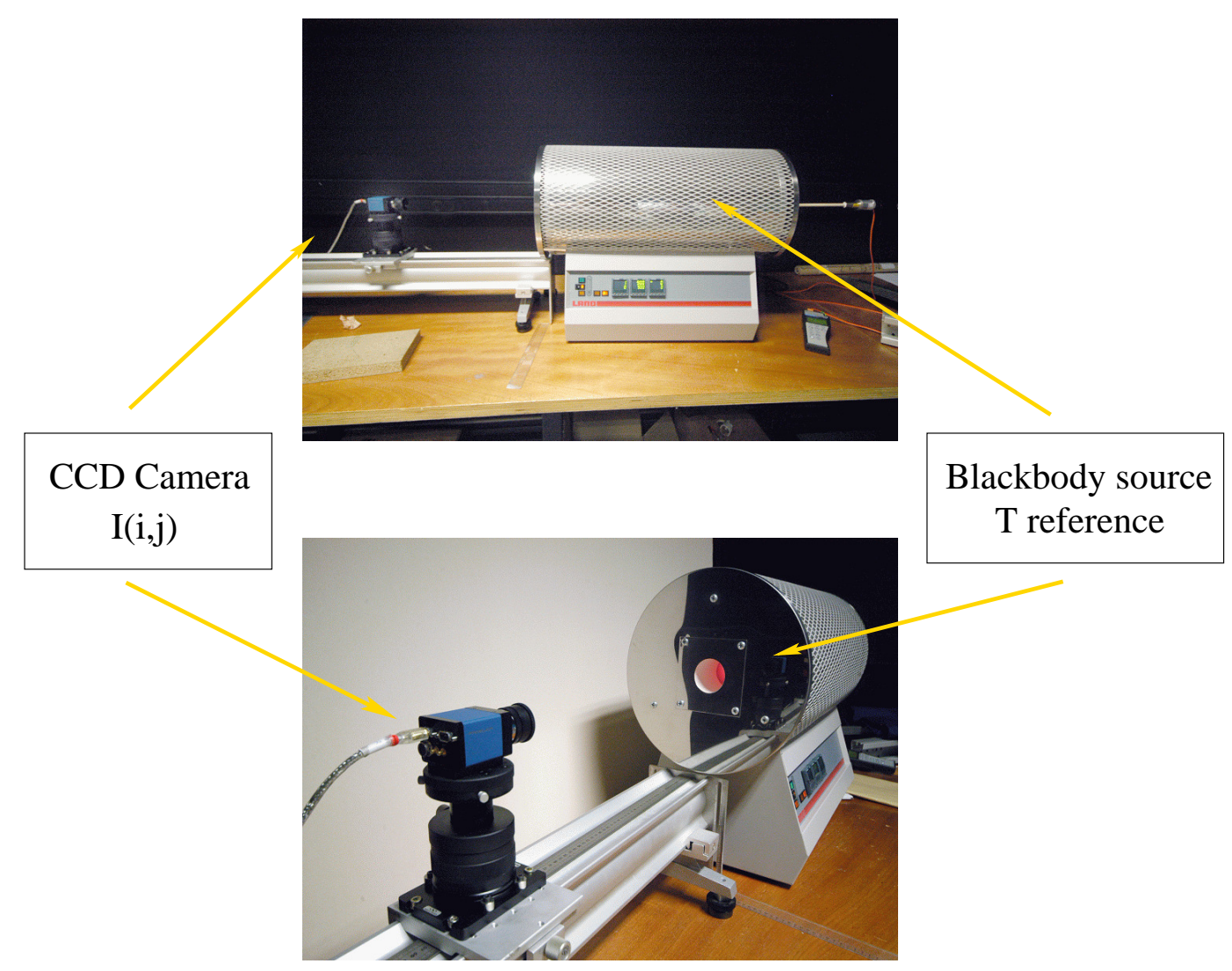

Fig. 3. Our radiometric calibration setup.

many processes involving high temperature measurements.

\section{Geometric calibration}

Camera calibration is an important task in 3-D computer vision, particularly when metric data are required for applications involving accurate dimensional measurements.

From a geometric point of view, a camera converts a 3 -D point $(X, Y, Z)$ in space to a $2-\mathrm{D}$ point $(i, j)$ in the image (see Figure 5 ).

Camera calibration consists in determining the elements that govern the relationship between the 2-D information $(i, j)$ that a camera perceives and the 


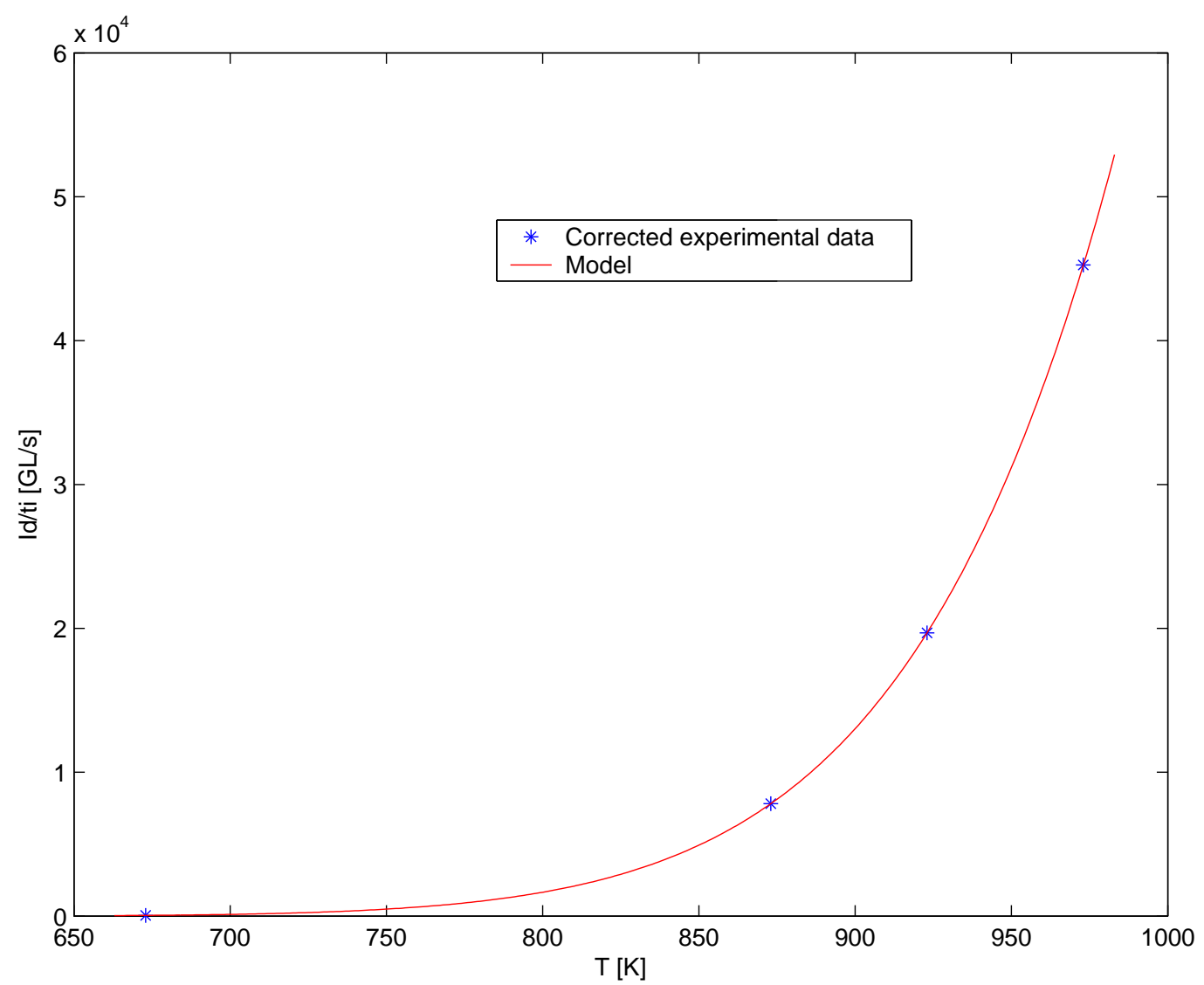

Fig. 4. A typical radiometric calibration curve (pixel intensity normalized by the integration time versus temperature). The corrected experimental data has been extracted from the corrected images (see Figure 2).

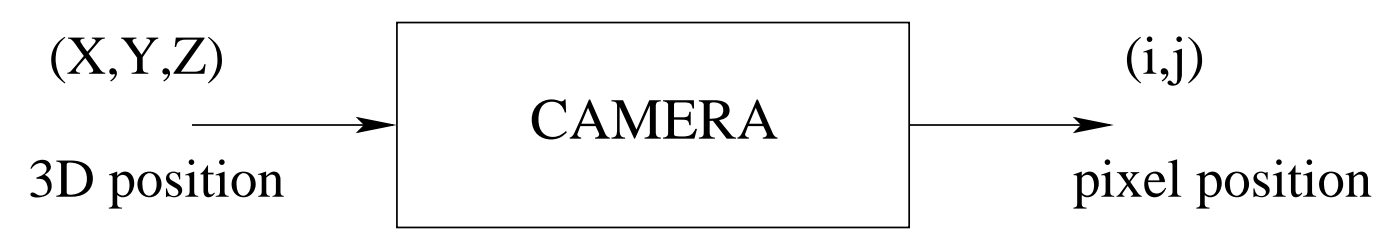

Fig. 5. From a geometric point of view, a camera converts a 3 -D point $(X, Y, Z)$ to a 2-D image point $(i, j)$.

3-D information $(X, Y, Z)$ of the imaged object. Generally this is performed by choosing a parametric model for the camera [34] and by estimating the parameters of this model by means of a calibration object, the 3 - $\mathrm{D}$ coordinates of which are known. 
Calibrating a camera involves determining its intrinsic parameters [34] and its position and orientation with respect to an arbitrary world reference frame. Calibrating a stereovision sensor made up of two cameras involves determining the intrinsic parameters of each camera and the relative position and orientation between the two cameras $[35,36]$.

These calibration data are required to compute, by triangulation, the 3-D coordinates of a point corresponding to matched pixels on the two stereo images.

In order to obtain accurate tri-dimensional measurements, lens distortion is taken into account in the geometric model of the cameras $[35,36]$. If a 3rd order radial lens distortion camera model is used, there are 20 independent parameters to be determined during the calibration process: 7 intrinsic parameters for each camera (the two coordinates in the image frame of the intersection of the optical axis with the image plane, the two scale factors along the vertical and horizontal axes of the image frame, and the three 3rd order radial lens distortion parameters) and 6 extrinsic parameters (the relative position and orientation between the two cameras). See $[35,36]$ for more details.

Regarding the calibration procedure, a flexible method is used: the calibration procedure only requires the cameras to observe a planar pattern shown at a few different orientations (see Figure 6). From these stereo pair of images, the calibration software computes automatically the required parameters in a few seconds [37].

After the radiometric and geometric calibration, the sensor is ready for the measurement of the shape $(X, Y, Z)$, the 3 -D displacement field $(U(X, Y, Z), V(X, Y, Z), W(X, Y, Z))$, the surface $\quad$ strain field 

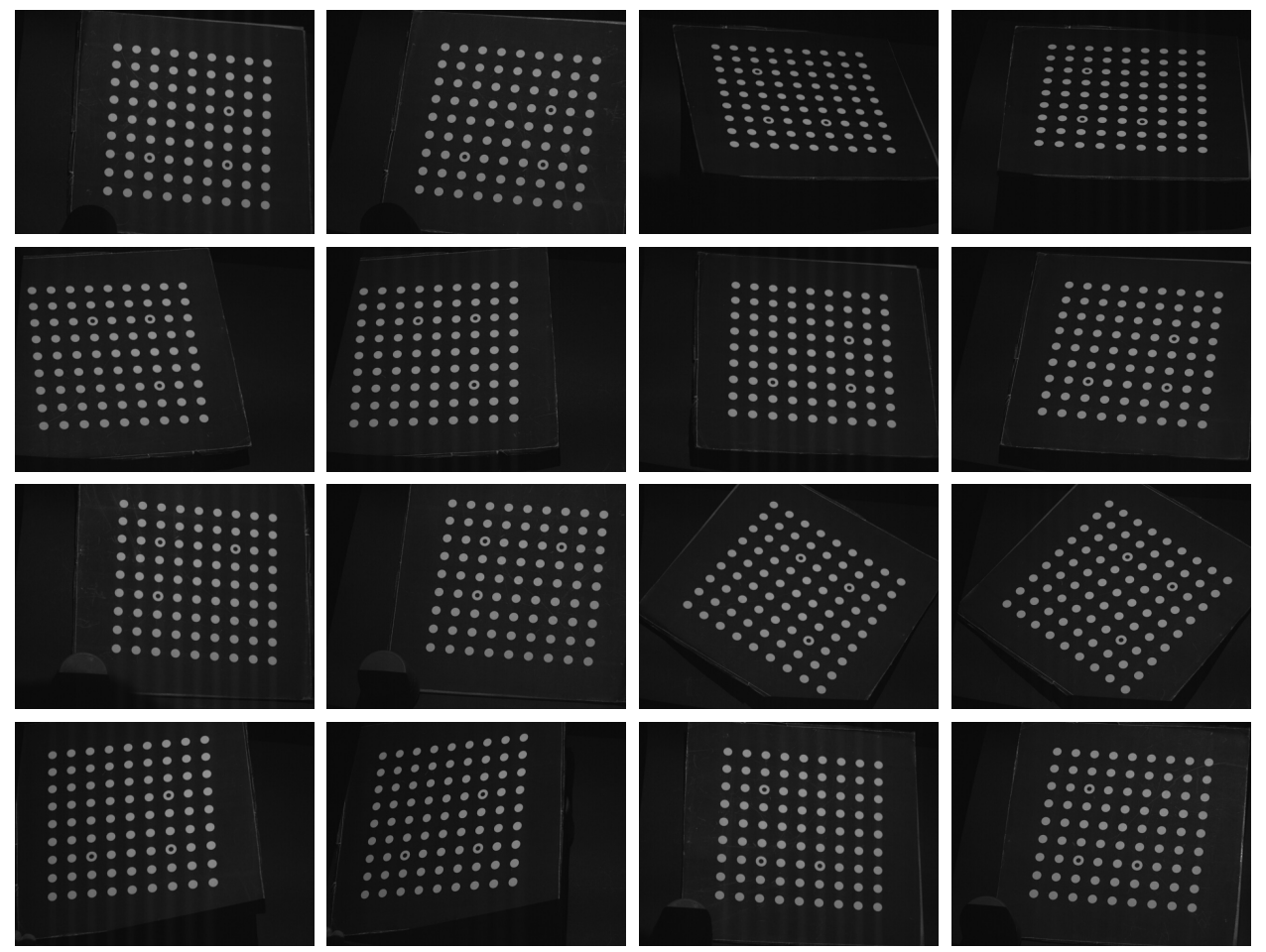

Fig. 6. A typical set of 8 stereo pairs of images used for the geometric calibration of the camera.

$\left(\varepsilon_{x x}(X, Y, Z), \varepsilon_{y y}(X, Y, Z), \varepsilon_{x y}(X, Y, Z)\right)$ and the thermal field $T(X, Y, Z)$ (see Figure 7).

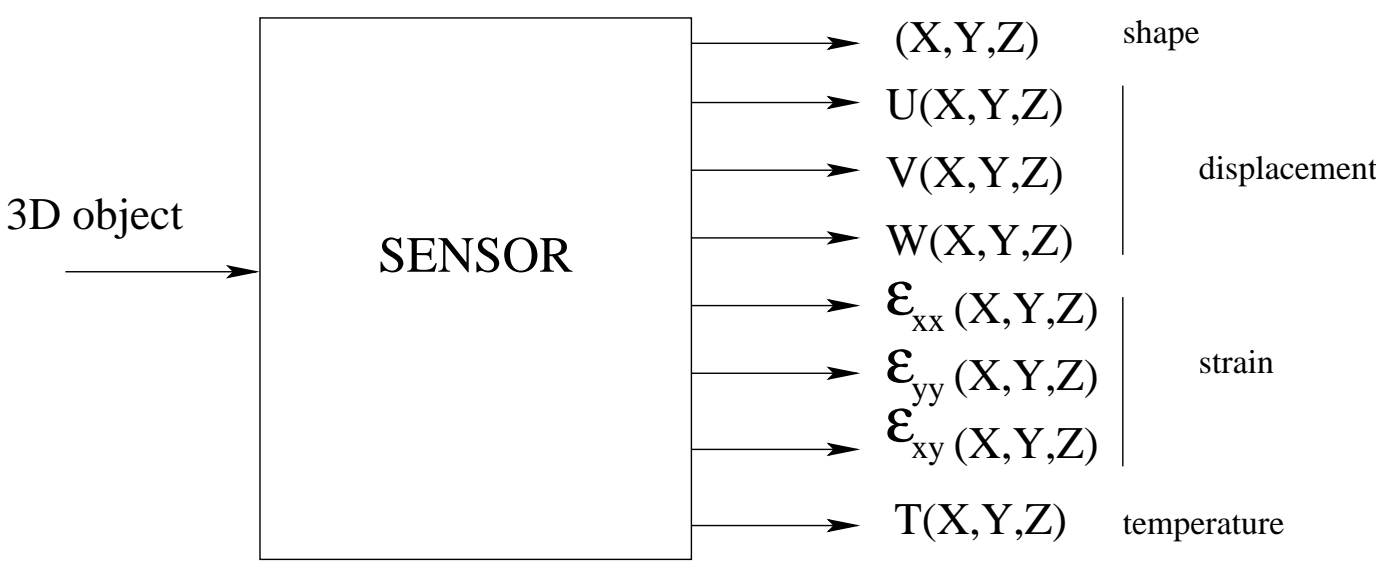

Fig. 7. For any 3-D object the sensor gives dimensional (shape/displacement/strain) and thermal (temperature) measurements. 


\section{Experimental setup}

The experimental setup used in order to validate the proposed method is illustrated in Figure 8. This setup is composed of three main elements: (a) a 3-D metallic mould (the object under study) enclosed in a fence for security reasons, (b) a heating device and (c) a stereovision rig to perform the noncontacting full-field shape/displacement/strain/temperature measurements.

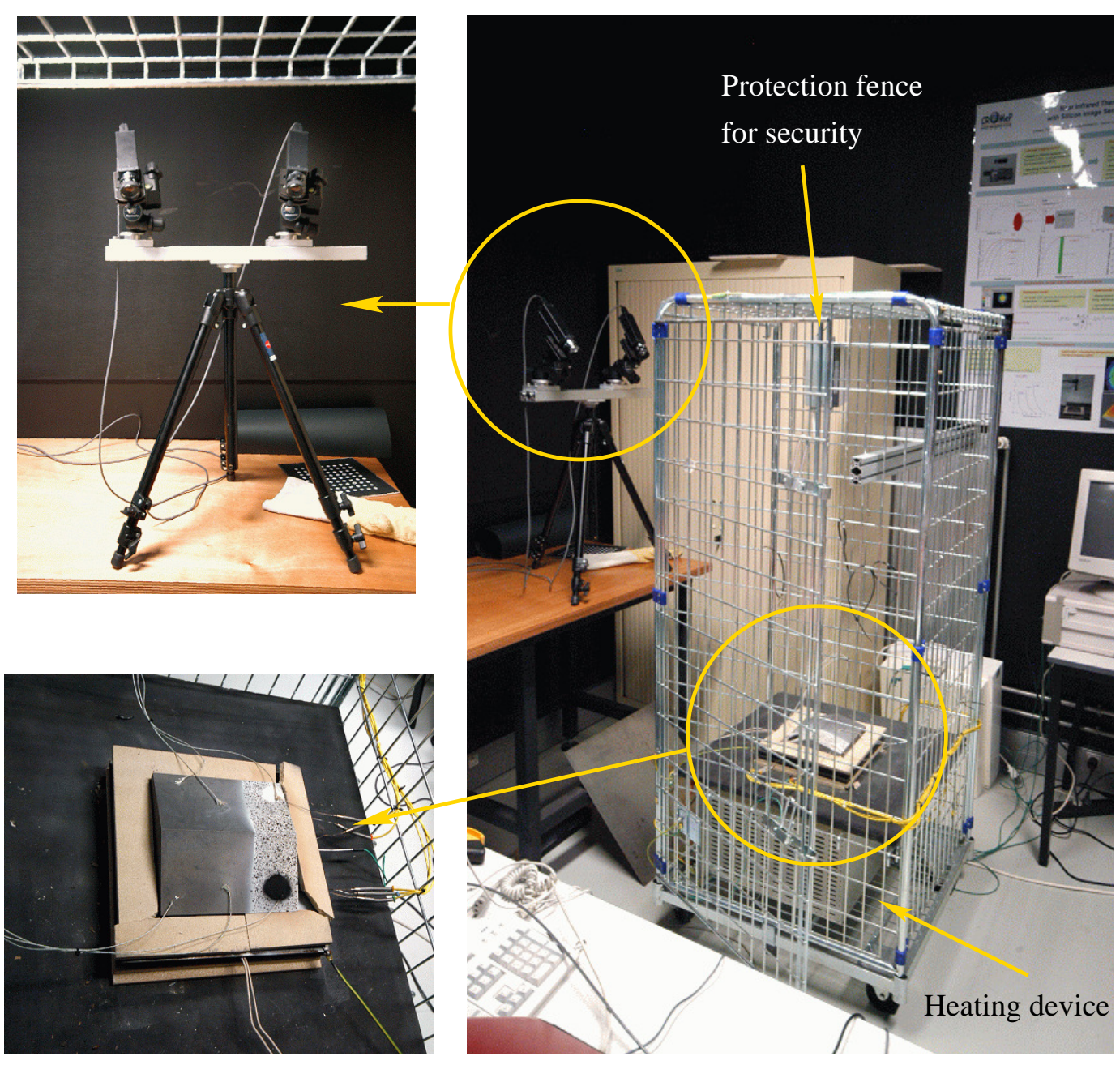

Fig. 8. Several views of the experimental setup showing the object under study (a metallic mould) and the stereovision rig used for shape/displacement/strain/temperature measurement.

The object under study is a non-planar metallic mould sizing about $200 \mathrm{~mm} \times$ 
$200 \mathrm{~mm}$, with a roof shape (two sloping planes) and a height of about $50 \mathrm{~mm}$.

In our experiments (see sections 5 and 6 ) the metallic mould is heated at several temperature levels ranging from 350 to $650{ }^{\circ} \mathrm{C}$ by a heating cartridge placed below the metallic mould. A set of 6 thermocouples were placed at the surface of the mould to provide classical temperature measurements ${ }^{2}$.

The stereovision rig is composed of two 10-bit off-the-shelf uncooled SONY XCD-SX910 cameras with a CCD resolution of $1280 \times 960$ pixels and a sensor pixel size of $4.65 \mu \mathrm{m} \times 4.65 \mu \mathrm{m}$. Computar $25 \mathrm{~mm} \mathrm{f} / 1.3$ lenses are used in the experiments. The distance between the cameras and the mould is about $1.5 \mathrm{~m}$. Images of the mould are taken by the synchronized cameras and the temperature of the mould is also recorded and synchronized with the image acquisition process.

Two sets of experiments were performed in order to demonstrate the capabilities of the proposed method.

\section{Shape/Temperature Measurement}

A first experiment in a static situation has been performed in order to show that the shape and the temperature field of the object under study could be obtained simultaneously. The mould was heated at a temperature of $450{ }^{\circ} \mathrm{C}$

$\overline{2}$ These thermocouples were used in previous experiments [20] to determine the influence of spatial variations of the emissivity of the mould and its evolution with temperature. In the present experiments, they have been only used to provide the temperature mean values used for the estimation of the coefficient of thermal expansion of the mould (see section 7). 
(set point imposed to the controller of the heating device).

The mould apparent temperature field is obtained thanks to the radiometric model (see section 2).

The shape is obtained using the stereo-correlation technique [36-43].

It is well known that Digital Image Correlation (DIC) requires that the object under study be textured (natural texture or artificial texture).

In this experiment, a synthetic speckle-pattern [44] is projected onto the mould using a video-projector ${ }^{3}$. As an example, Figure 9 shows an object and the same object with a speckle pattern projected onto it using a video-projector.

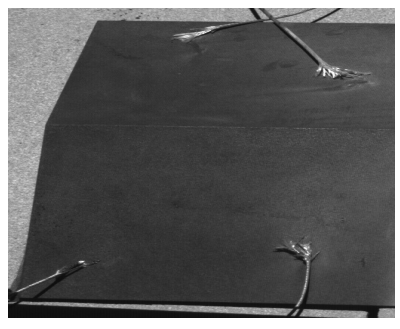

Object

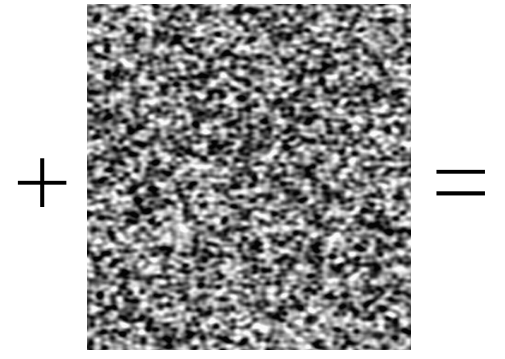

Video-projected speckle-pattern

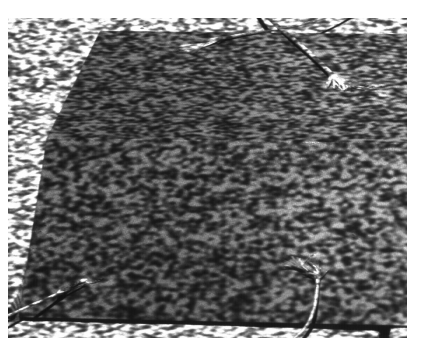

Object with video-projected speckle-pattern

Fig. 9. For shape measurement applications, the speckle pattern can be projected onto the object using a video-projector.

Figure 10 shows a stereo pair of images of the mould under study with a speckle pattern video-projected onto it. The thermocouples that were placed at the surface of the mould can be seen on that picture.

A correlation-based image matching algorithm was used to compute a disparity $\operatorname{map}^{4}$ (see Figure 10). On Figure $10, d_{i}=i^{\prime}-i$ is the horizontal disparity $\overline{3}$ Note that the video-projection of the speckle-pattern onto the surface of the mould allows to obtain the shape, but not the strains. See section 6 for strain measurements.

4 A stereo disparity map indicates the correspondences between left and right im- 
and $d_{j}=j^{\prime}-j$ is the vertical disparity corresponding to the pair of matched pixels.

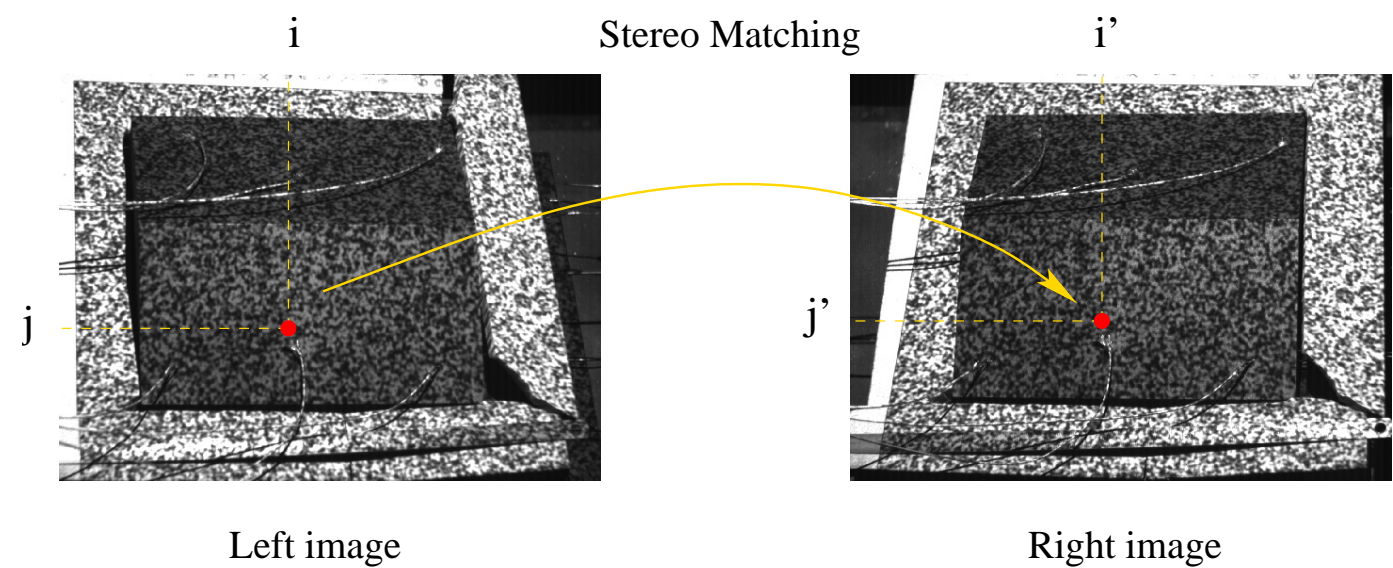

Fig. 10. A correlation-based image matching algorithm was used to find the stereo-corresponding pixels within a given stereo pair of images.

The methodology is as follows (see Figure 11):

(1) first, a stereo pair of images with speckle-pattern lighting is acquired. From this stereo pair, the 3 -D shape of the object, i.e. the $(X, Y, Z)$ map, can be computed by stereo-correlation:

$$
(i, j) \text { and }\left(i^{\prime}, j^{\prime}\right) \longrightarrow(X, Y, Z)
$$

(2) then, another stereo pair of images is acquired (a single image could be enough). From this stereo pair, the thermal map can be obtained ${ }^{5}$ :

ages. The horizontal (vertical) disparity is defined as the difference between the column (row) coordinates of the pixel locations of corresponding pixels in the left and right image of a stereo pair. It should be noted that a subpixel correlation-based image matching algorithm is used so the disparity is a real value and not an integer value.

5 As shown on Figure 11, the image provided by the left camera has been used to compute the thermal map because the left camera had been radiometrically 


$$
(i, j) \longrightarrow T
$$

With speckle-pattern lighting
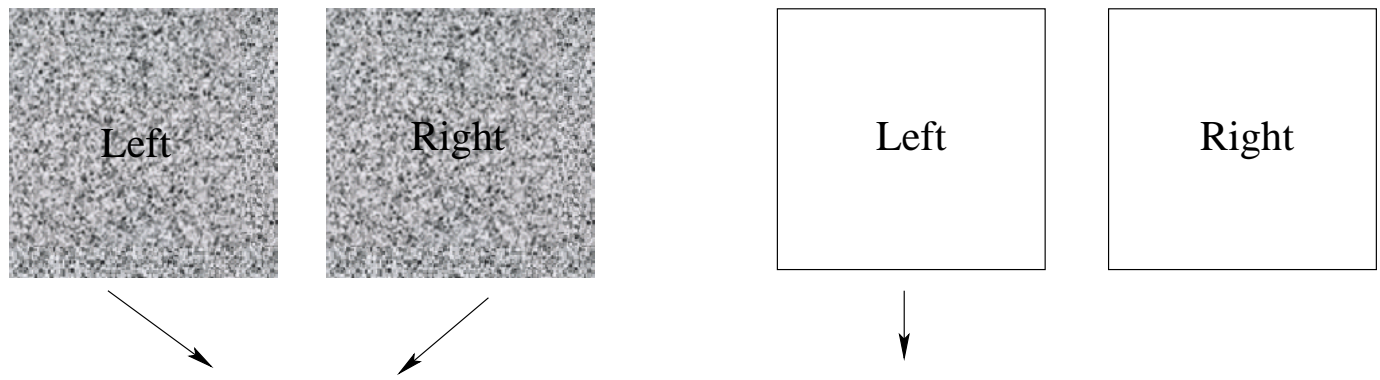

SHAPE

THERMAL MAP
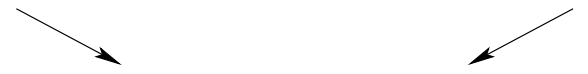

SHAPE + TERMAL MAP

Fig. 11. Shape/Temperature measurement using the same sensor.

As the same sensor in the same position is used for acquiring the two stereo pair of images, the data fusion is intrinsic: to any pair of matched pixels the 3-D position $(X, Y, Z)$ of the corresponding point in space and the temperature $T$ of this point can be associated. Thus, the 3-D shape of the specimen and also the temperature of each point of its surface is obtained. Indeed, from equations (3) and (4), we have:

$$
(i, j) \text { and }\left(i^{\prime}, j^{\prime}\right) \longrightarrow(X, Y, Z, T(X, Y, Z))
$$

Figure 12 shows a $3-\mathrm{D}$ view of the $3-\mathrm{D}$ shape of the mould. The white areas on the left figure correspond to non-reconstructed areas due to the thermocouples that were placed at the surface of the mould.

calibrated beforehand. If the two cameras of the stereovision sensor had been radiometrically calibrated, any of the two images could have been used. 

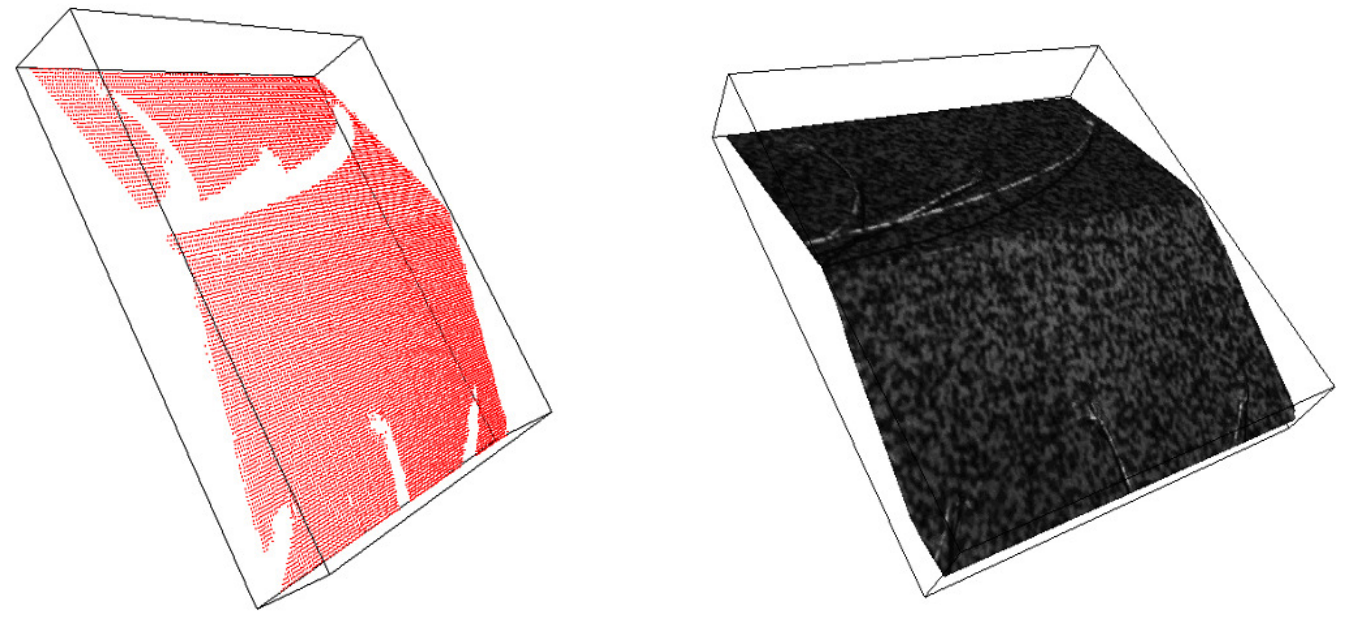

Fig. 12. 3-D shape of the mould obtained by stereo-correlation ; (left) the cloud of 3-D points and (right) the image texture overlaid onto the 3-D shape.

The thermal map $T(X, Y, Z)$ can be also displayed onto the 3-D shape (see Figure 13).

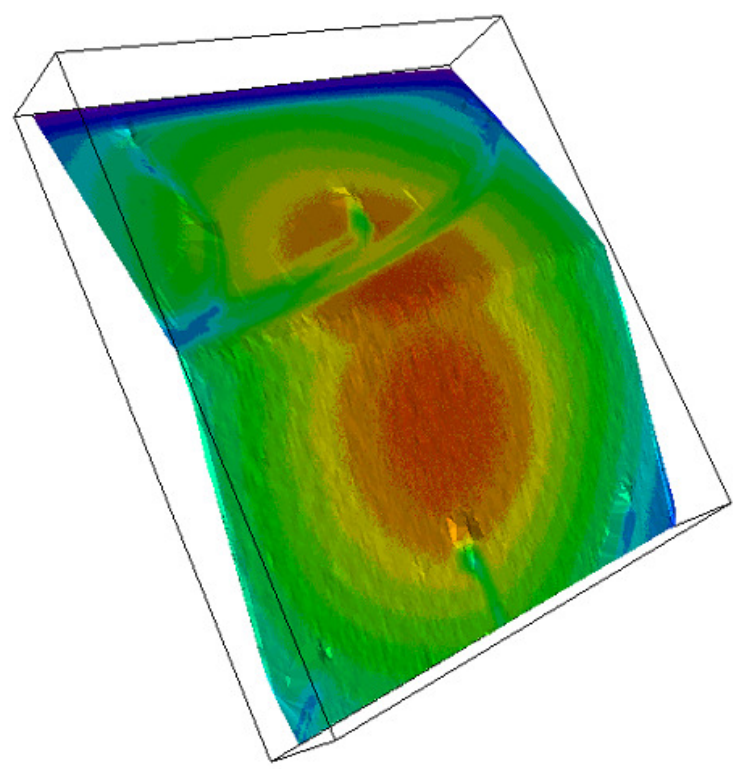

\begin{tabular}{|l|l|}
\hline & 405 \\
\hline & 404 \\
\hline 402 \\
\hline 400 \\
\hline 397 \\
\hline 395 \\
\hline 392 \\
\hline 389 \\
\hline 386 \\
\hline 383 \\
\hline 378 \\
\hline 374 \\
\hline 368 \\
\hline 361 \\
\hline 352 \\
\hline 338 \\
\hline 301 \\
\hline
\end{tabular}

Fig. 13. Thermal map displayed onto the 3-D shape. 


\section{Displacement/Strain/Temperature Measurement}

A second experiment has been carried out in a non-static situation (different levels of temperature) in order to show that the shape, the displacement, the strain and the temperature fields could be obtained simultaneously.

The shape $(X, Y, Z)$, the $3-\mathrm{D}$ displacement field $(U, V, W)$ and the surface

strain field $\left(\varepsilon_{x x}, \varepsilon_{y y}, \varepsilon_{x y}\right)$ are obtained using the stereo-correlation technique [36-43].

As we are now interested in the displacement and strain fields, the speckle pattern can no longer be video-projected onto the object. The speckle pattern needs to be stuck to the object surface in order to follow the object deformation. Prior to performing the experiment, a speckle pattern was created at the surface of the mould by using spray paint (a random black-and-white speckle pattern having a spatial variation in intensity that is appropriate for DIC). In fact, it was decided to paint only one part of the mould and the other part was left rough (see Figure 14).

As we are now in a non-static situation, a sequence of stereo pair of images is acquired. If the object is subjected to a varying temperature, the thermal displacement/strain fields are obtained. If the object is subjected to a mechanical load, the mechanical displacement/strain fields are obtained. Of course, if the object is subjected to a varying temperature and a mechanical load, the resulting displacement/strain fields are obtained. In the present work, the mould was heated at different temperature levels and two stereo pair of images were acquired at each temperature level. By processing the images, the 3-D shape of the mould, its 3-D displacement and strain fields and the temperature of 


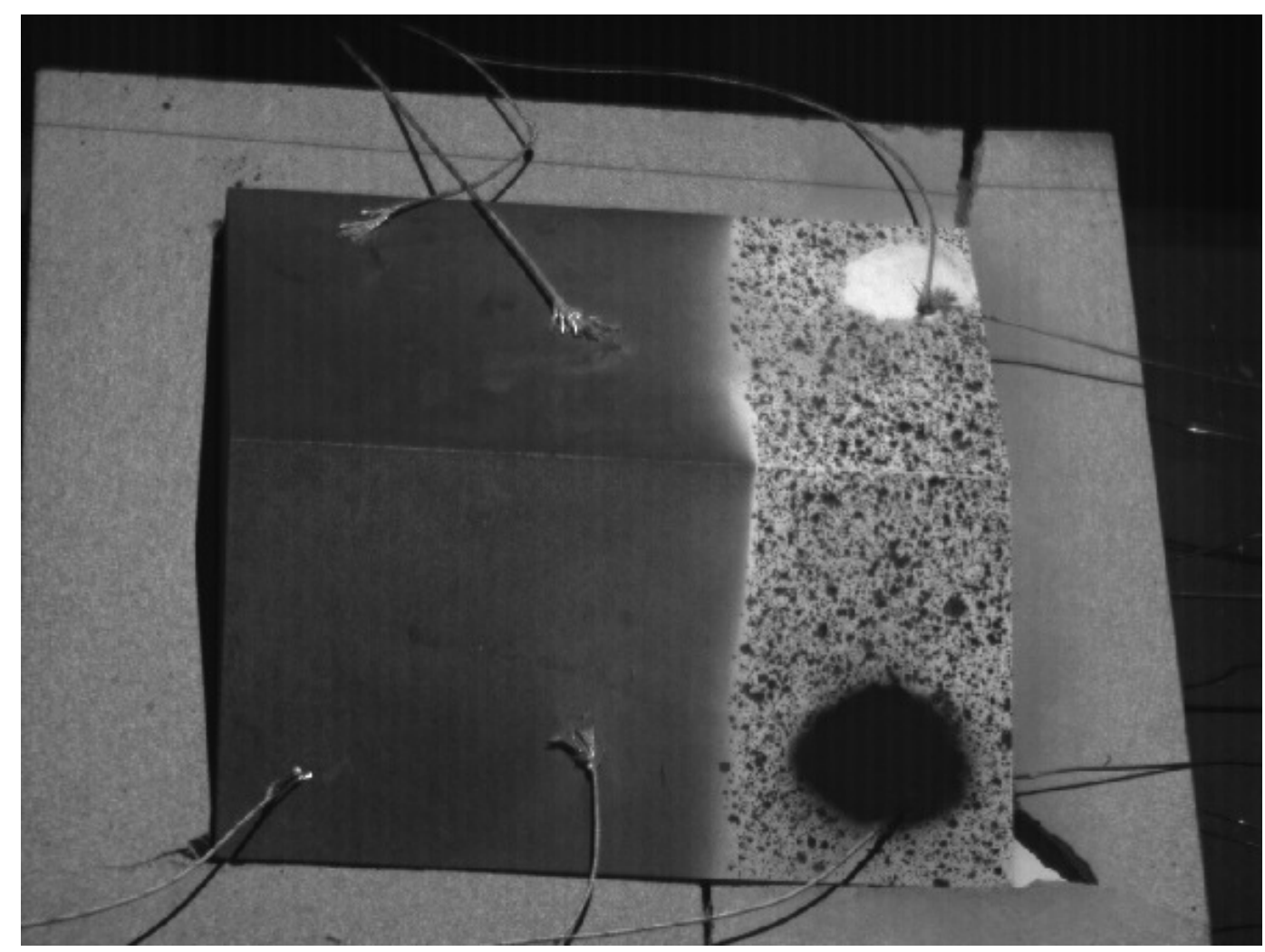

Fig. 14. The right side of the mould was painted for the second experiment in order that the displacement/strain fields could be obtained.

each point of its surface are obtained:

$$
(i, j) \text { and }\left(i^{\prime}, j^{\prime}\right) \longrightarrow\left(X, Y, Z, U, V, W, \varepsilon_{x x}, \varepsilon_{y y}, \varepsilon_{x y}, T\right)
$$

Figure 15 shows two thermal maps obtained for two levels of temperature loading $\left(344^{\circ} \mathrm{C}\right.$ and $\left.469^{\circ} \mathrm{C}\right)$.

Figure 16 shows a $3-\mathrm{D}$ view of the $3-\mathrm{D}$ shape of the mould obtained by stereocorrelation. As the left side of the mould was not painted, its 3-D shape was obtained using the video-projection of a synthetic speckle-pattern.

Any computed value $\left(X, Y, Z, U, V, W, \varepsilon_{x x}, \varepsilon_{y y}, \varepsilon_{x y}, T\right)$ can be overlaid onto the image or onto the 3-D shape. As an example, Figure 17 shows the $W$ map 


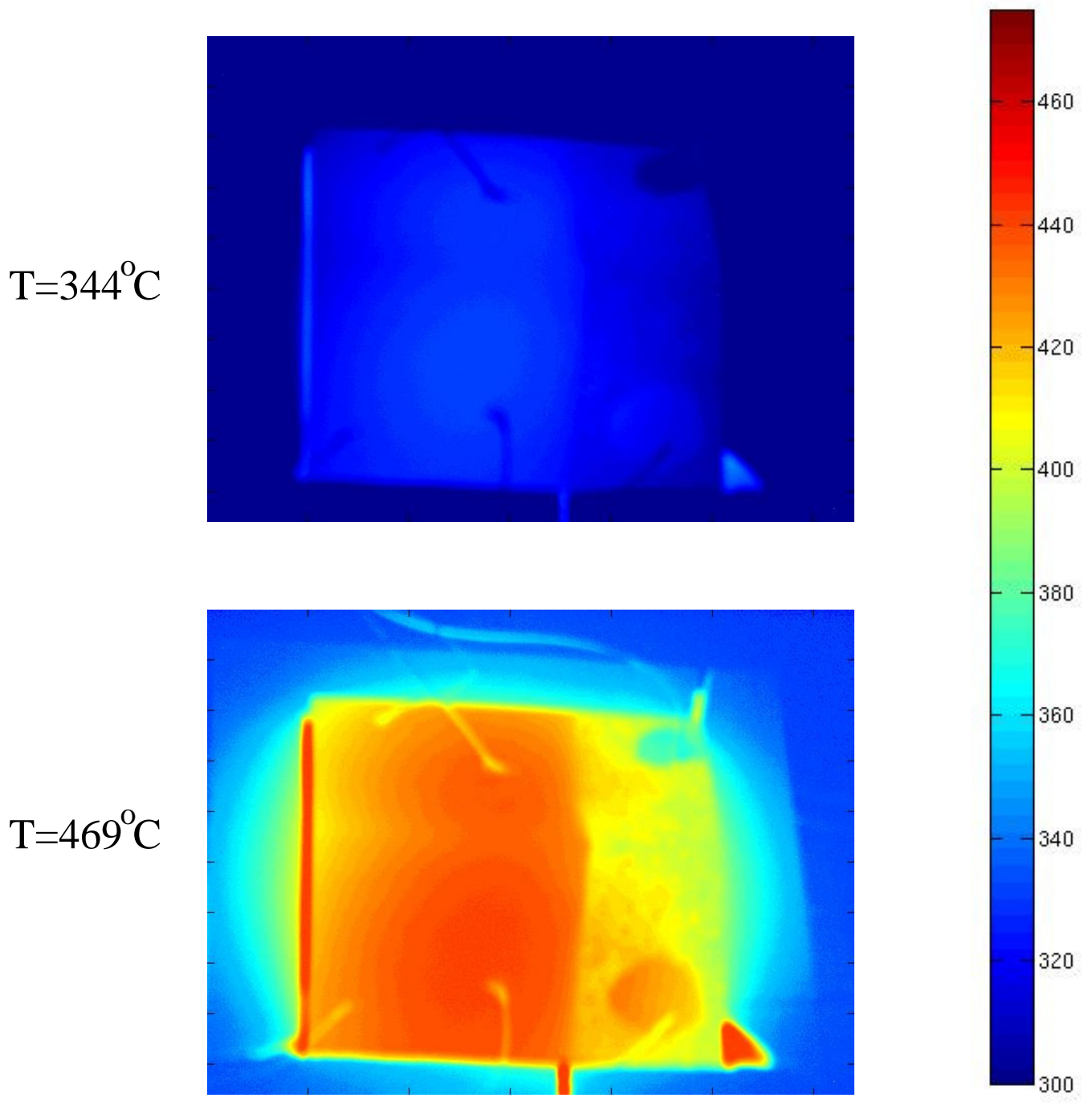

Fig. 15. Two thermal maps corresponding to two levels of temperature loading.

(displacement along the $Z$ axis, which is the out-of-plane direction) overlaid onto the image and onto the 3-D shape, for a temperature varying between the ambient to $344{ }^{\circ} \mathrm{C}$. The displacement/strain fields could only be computed on the painted right side of the mould.

Figure 18 shows the thermal map overlaid onto the 3-D shape. 

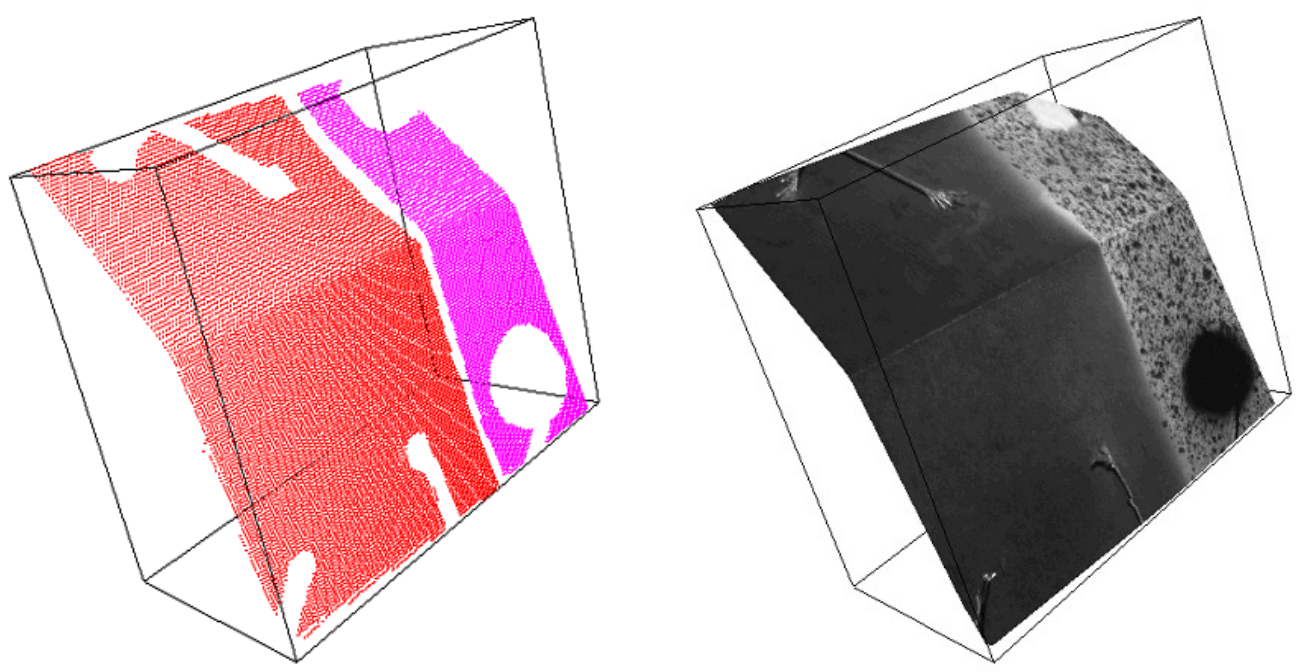

Fig. 16. 3-D shape of the mould obtained by stereo-correlation. (left) the cloud of 3-D points and (right) the image texture overlaid onto the 3-D shape.
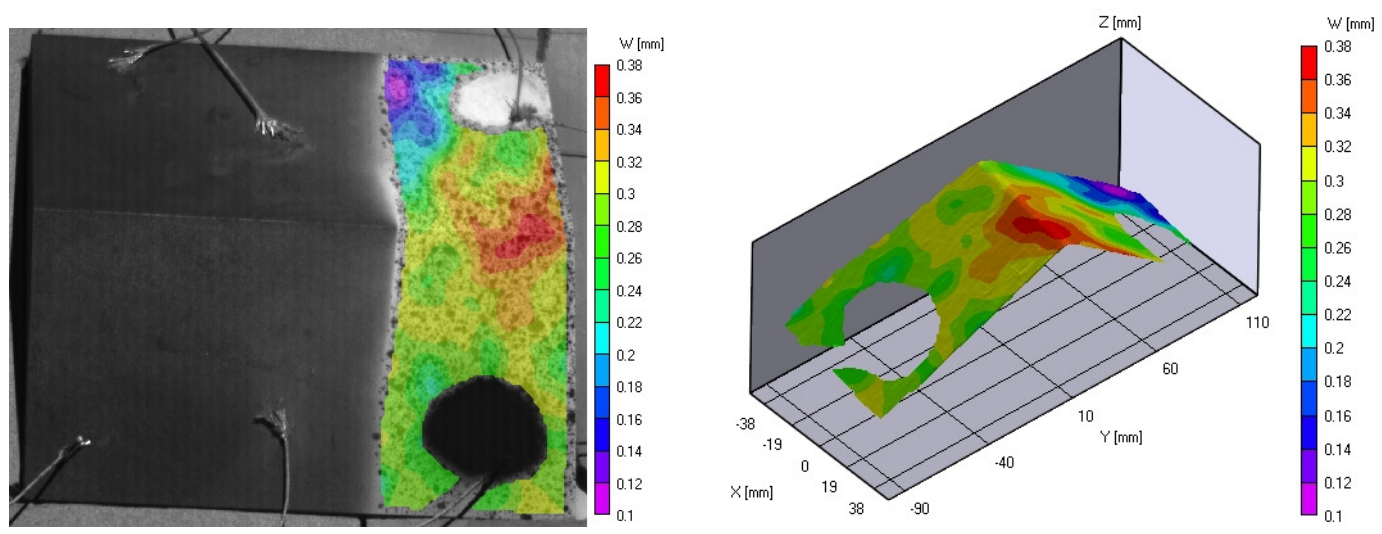

Fig. 17. Any computed value (here the $W$ out-of-plane displacement value) can be overlaid onto the image (left) or onto the 3 -D shape (right).

\section{$7 \quad$ Discussion of results}

In this section, some issues regarding the measurements and some improvements that could be made are discussed. 

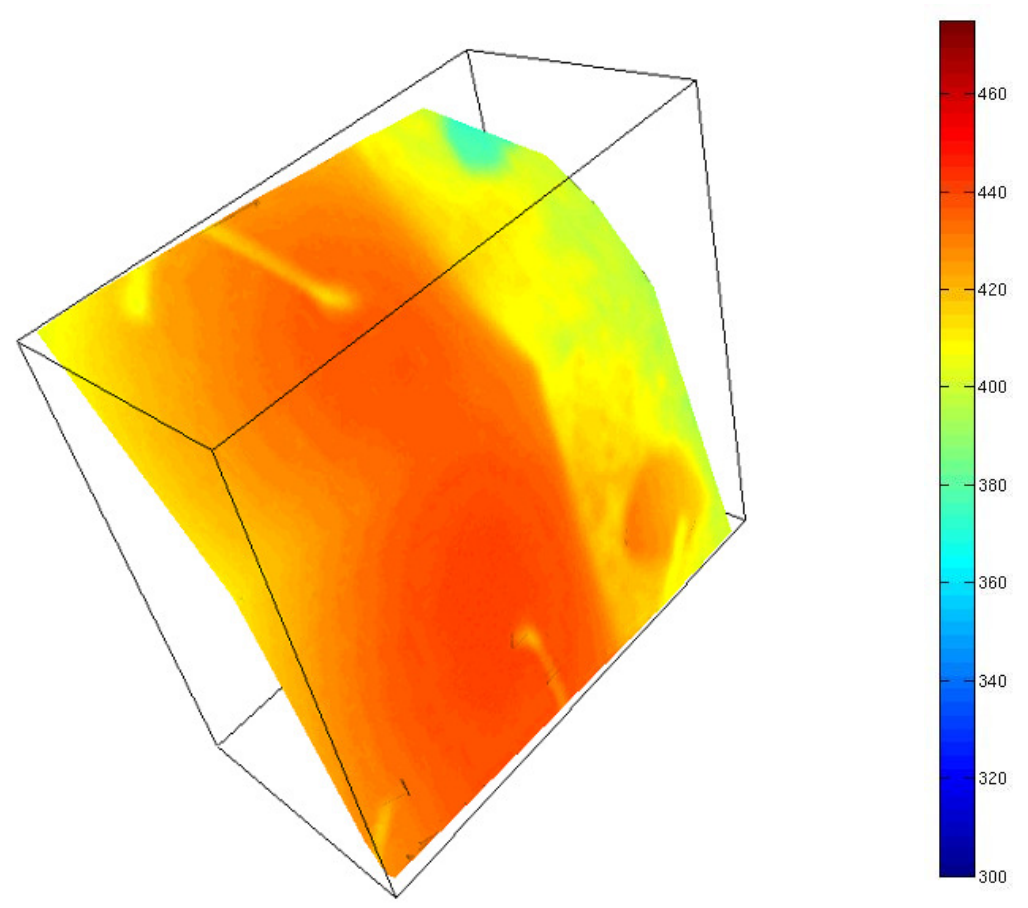

Fig. 18. Thermal map displayed onto the 3-D shape.

\subsection{Temperature measurements}

The main purpose of this work was to show the feasibility of providing both dimensional AND thermal measurements with the same type of camera. At this stage, we have focused our attention on the measurement of apparent temperatures.

In the range 300 to $650{ }^{\circ} \mathrm{C}$, using a blackbody source in a calibration situation and a 3-parameters radiometric model, the apparent temperature measurement accuracy is less than $1^{\circ} \mathrm{C}$ at an observation distance of $1 \mathrm{~m}[20,21]$. Using a 4-parameters radiometric model, the same performances can be reached in the range 300 to $1000{ }^{\circ} \mathrm{C}$. Such performances for temperature measurements using off-the-shelf low-cost uncooled CCD cameras have been obtained thanks to the accurate radiometric modelling of the camera and because particular attention has been paid to each possible source of error. 
In most of experimental mechanics applications, the true temperatures need to be known. Measuring a true temperature field on non planar objects, involves to take into account the following additionnal data:

- the surface emissivity which can be either found in the literature for only a given material and a given wavelength, or measured during a preliminary step. For opaque materials, an on-line estimation of the emissivity can be obtained by several techniques like pyroreflectometry [45], bichromatic or polychromatic analysis of thermal radiation [33], etc. Nevertheless, it should be noted that estimating the emissivity remains an open problem and has still not received an universal solution because the emissivity coefficients generally depend themselves on the temperature, on the surface variations and thus they change during the processing steps.

It has been shown that CCD cameras operating in the NIR range are much less sensitive to the emissivity of the observed surface [46] than infrared ones and, in some applications, considering the emissivity as constant is not so penalizing.

In $[20,21]$, we have carried out some experiments on a metallic mould, with a uniform surface, heated from 300 to $650{ }^{\circ} \mathrm{C}$. By assuming a constant emissivity equal to 0.8 , true temperature field measurements have been obtained with an accuracy of $\pm 3{ }^{\circ} \mathrm{C}$ at an observation distance of $1 \mathrm{~m}$. This little loss of accuracy (compared to the apparent temperature measurement accuracy) is due to the phenomenon of oxydation of the mould surface which is in discordance with the hypothesis of constant emissivity.

For strain measurements using the DIC technique a speckle pattern is created at the surface of the mould by using spray paint. The variations in surface pattern and the associated change in thermal emissivity will of 
course affect the accuracy of the true temperature computation. Two large white and black areas have been painted at the surface of the mould (see Figure 14). These areas will be used in future work to determine the emissivity of the paint.

- the radiative exchanges between the specimen surfaces (for instance interreflection for non convex objects), depending on optical properties and the suface normals, as in a radiosity model [47], require to take into account the shape factor of the specimen under study. The 3-D information provided by the stereovision sensor could provide the surface normals required for computing this temperature shape coefficient.

Of course, the computation of true temperature fields is our final objective and the issues discussed above are now being investigated.

\subsection{Kinematical measurements}

The shape or displacement measurement relative accuracy in object space (the accuracy of coordinate determination divided by the size of the object) achieved using stereo-correlation under controlled laboratory conditions at room temperature is about $1 / 50000$ (see [36] for a more detailed discussion on 3-D reconstruction accuracy).

The strains are computed by numerical differentiation from the displacements measured at several points distributed over a mesh. The accuracy of the strain computation depends on many factors: the discrete derivation scheme used, the accuracy of the displacement measurement, and the computation basis (mesh element spacing) [38]. The strain measurement accuracy using stereo- 
correlation under controlled laboratory conditions at room temperature can be about $0.05 \%$ (500 $\mu$ strain) with triangular elements measuring 50 pixels $[38]$.

The accuracy of camera-based kinematical measurements can be highly affected in elevated temperatures conditions. One of the main problem is air convection that causes distortions of the specimen's image. Lyons et al. [48] have demonstrated the capability of DIC for measuring strains at temperatures up to $650{ }^{\circ} \mathrm{C}$ with the same level of accuracy that is obtainable under ambient conditions. In their work, the specimen is placed in a furnace. For minimizing the air convection phenomenon that takes place between the furnace window and the camera, they have used a fan that mixed the air so that the air temperature and the index of refraction remained constant. It should be noted that the temperature of the furnace window does not exceed $120^{\circ} \mathrm{C}$.

In the present work, we do not use any furnace and we observe directly a specimen heated between 300 and $470{ }^{\circ} \mathrm{C}$. A first experiment was conducted without using any fan and the analysis of the displacement/strain fields showed that these fields were not stable with time. A new experiment was performed and 50 stereo pairs of images at 3 levels of temperature loading were acquired. For the higher temperature, two sets of 50 stereo pairs of images were acquired, with and without using a fan. A total of 200 stereo pairs of images were acquired (see Figure 20).

Figure 19 shows the area that has been used to analyze the displacement and strain fields. For instance, the mean $\varepsilon_{y y}$ strain has been computed on this area. Figure 20 shows the mean $\varepsilon_{y y}$ strain evolution over the sequence of 50 images acquired at each level of temperature loading. First, air convection increases 


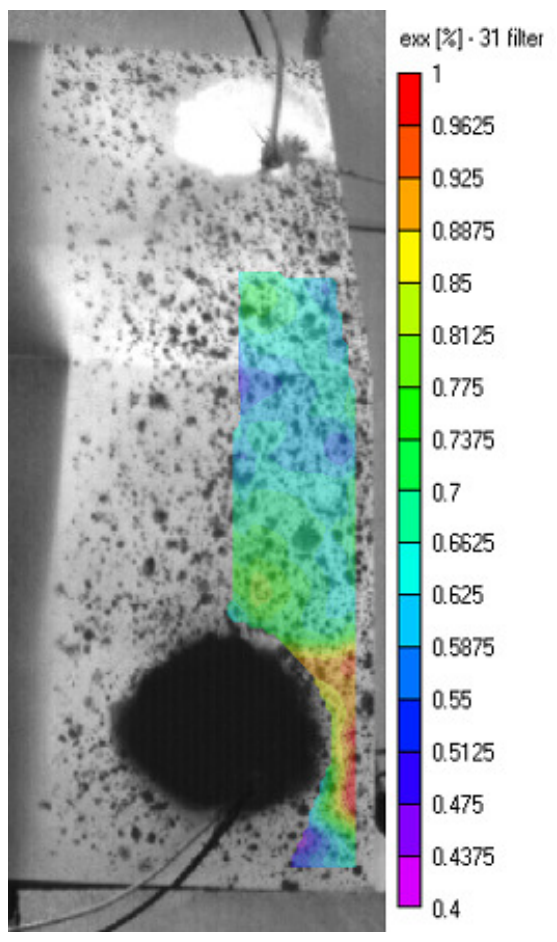

Fig. 19. The area that has been used to analyze the strain field.

with the temperature of the mould as strain curves become more noisy as the temperature increases. Second, from the strain curve obtained at a temperature of $469{ }^{\circ} \mathrm{C}$ it can be seen that very much more stable strain values are obtained when a fan is used.

From the mean strain values computed at the 3 temperature levels, the coefficient of thermal expansion (CTE) of the material could be estimated. The computed value is in good agreement with the CTE of the material under concern.

In these experiments, the DIC-based strain measurements have been performed at temperatures ranging from 300 to $470{ }^{\circ} \mathrm{C}$. As demonstrated by Lyons et al. [48], we have shown that the use of a fan minimizes the effect of convection. Further experimemts need to be carried out in order to assess quantitatively the accuracy of the measurements and to determine the higher 


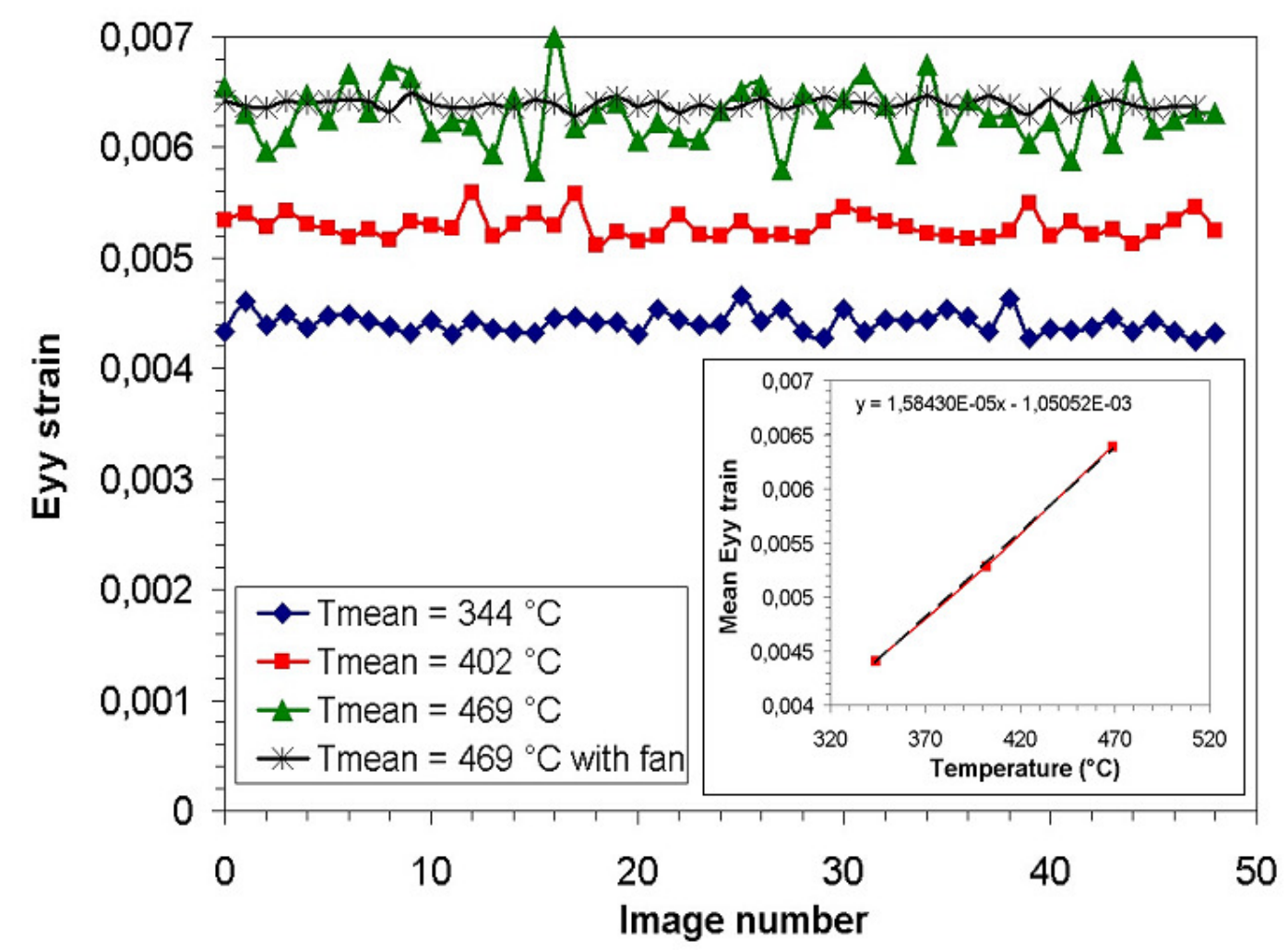

Fig. 20. Strain analysis: from the mean $\varepsilon_{y y}$ strain evolution over the sequence of 50 images acquired at each level of temperature loading it can be seen that very much more stable strain values are obtained when a fan is used. Estimation of the coefficient of thermal expansion (CTE) of the material from the mean strain values computed at 3 temperature levels (mean temperature given by the thermocouples).

temperature for which an acceptable accuracy can be still obtained.

Another problem that can arise at high temperature, e.g up to $650{ }^{\circ} \mathrm{C}$ for steel, is a loose of contrast in the images due to the IR emission. This can be tackled by different ways: (1) on-line control of the camera integration time, (2) use of an IR filter, (3) use of a normalized cross-correlation coefficient in the DIC method which is known to be adapted to situations where contrast and brightness evolutions are hard to avoid (such a correlation coefficient is already used in our experiments). 


\subsection{Transient events}

As mentioned in section 2.2, the integration time of the camera is controlled in-line in order to tackle with a wide range of temperatures. Long integration times could be a problem for the study of transient events. Nevertheless, it should be noted that the required integration time decreases when the temperature increases and very short integration times are used in practice for high temperatures $\left(0.5 \mathrm{~s}\right.$ for $500{ }^{\circ} \mathrm{C}, 63 \mathrm{~ms}$ for $700{ }^{\circ} \mathrm{C}, 15 \mathrm{~ms}$ for $750{ }^{\circ} \mathrm{C}$, etc. $)$.

\section{Conclusion}

An innovative method to compute simultaneously, and with the same type of camera, the shape, the displacement, the strain and the temperature fields of an object has been proposed.

The results clearly show the potentialities of the proposed technique. Its main advantages are:

- a simplified instrumentation: the same sensor gives dimensional/kinematical AND thermal measurements

- an intrinsic spatial coherence: each pixel of the camera observes the kinematic AND the thermal behavior of the specimen; the data fusion is intrinsic

- the use of off-the-shelf low-cost high-resolution uncooled CCD cameras for thermal measurements

It should be noted that the method presented in this paper utilizes two CCD cameras (stereovision) in order to provide simultaneously the shape, the $3-\mathrm{D}$ displacement/strain and temperature fields. Of course, the same methodology 
could be used with a single CCD camera to get the 2-D displacement/strain and temperature fields of any planar object subjected to a thermo-mechanical load.

At this stage, we have focused our attention on the measurement of apparent temperatures. Our efforts are now focused on two main issues: true temperature measurements and accuracy assessment of kinematical measurements at high temperature.

\section{Acknowledgments}

The authors are grateful to Didier Adé for his assistance in conducting the experiments and to Florian Bugarin for his help in processing some experimental data.

\section{References}

[1] V. Velay, G. Bernhart, D. Delagnes and L. Penazzi (2005) A continuum damage model applied to high-temperature fatigue lifetime prediction of a martensitic tool steel. Fatigue \& fracture of engineering materials \& structures, 28:10091023.

[2] V. Velay, G. Bernhart and L. Penazzi (2006) Cyclic behavior modeling of a tempered martensitic hot work tool steel. International Journal of Plasticity, 22:459-496.

[3] F. Nazaret, T. Cutard and G. Bernhart (2004) Thermomechanical behaviour of a fibre-reinforced refractory concrete: tests and analysis. M. Di Prisco, R. 
Felicetti and G.A. Plizzari (eds.). Proceedings of the Sixth RILEM Symposium on Fibre-Reinforced Concretes, 689-698, Varenna (Italy).

[4] H. Marzagui, T. Cutard, E. Yeugo-Fogaing, M. Huger, C. Gault, N. Prompt and C. Deteuf (2004) Microstructural changes and high temperature mechanical behavior of an andalusite based low cement refractory castable. M. Rigaud and C. Allaire (eds.). Proceedings of Advances in Refractories for the Metallurgical Industries IV (COM'2004), 331-345, Hamilton (Canada).

[5] H.A. Bruck, H.W. Schreier, M.A. Sutton, Y.J. Chao, X. Dengand and M. Davoud (1998) Distortion in GMAW of Thin Plates: Temperature and 3-D Deformation Measurements Using High-Speed Thermal Imaging and Stereoscopic Video Imaging. Proceedings of 5th International Conference on Trends in Welding Research, 967-971, Pine Mountain, GA (USA).

[6] G. Dusserre, F. Schmidt, G. Dour and G. Bernhart (2005) Thermo-mechanical stresses in cast steel dies during glass pressing process. Journal of Materials Processing Technology, 162-163:484-491.

[7] S. Baleix, Y. Le Maoult, S. Frenois, Y. Marcel, P. Lours and G. Bernhart (1999) Simulation of service life cycle induced thermomechanical stresses in a superplastic forming tool. Proceedings of Third International Congress on Thermal Stresses, 317-320, Krakow (Poland).

[8] F. Nazaret, T. Cutard and G. Bernhart (2004) Mechanical behavior of ceramic materials for SPF toolings. Proceedings of European Conference on Superplastic Forming (EuroSPF04), Albi (France).

[9] S. Claudinon, P. Lamesle, J.-J. Orteu and R. Fortunier (2002) Continuous insitu measurement of quenching distortions using computer vision. Journal of Materials Processing Technology, 122:69-81.

[10] G. Cloud (1998) Optical Methods of Engineering Analysis. Cambridge 
University Press, New York (USA), ISBN 0-521-45087-X.

[11] P.K. Rastogi (1999) Photomechanics. Springer Verlag, Berlin (Germany), ISBN 3-540-65990-0.

[12] M. Grédiac (2004) The use of full-field measurement methods in composite material characterization: interest and limitations. Composites Part A, 35:751761.

[13] Y. Surrel (2004) Full-field optical methods for mechanical engineering: essential concepts to find one's way. Invited keynote at the 2nd International Conference on Composites Testing and Model Identification, Bristol (UK).

[14] H.J. Kostkowski and R.D. Lee (1962) Theory and Methods of Optical Pyrometry. National Bureau of Standards, Reinhold Publishing Corporation.

[15] G. Holst (1998) Testing and evaluation of infrared imaging systems. JCD Publishing, 2nd Edition.

[16] S. Colantonio, G. Pieri, O. Salvetti, M. Benvenuti, S. Barone and L. Carassale (2006) A method to integrate thermographic data and 3D shapes for Diabetic Foot Disease. Proceedings of 8th International Conference on Quantitative Infrared Thermography (QIRT), Padova (Italy).

[17] W. Satzger, G. Zenzinger and V. Carl (2006) Quantitative 3D-thermography. Proceedings of 8th International Conference on Quantitative Infrared Thermography (QIRT), Padova (Italy).

[18] B. Wattrisse, J.-M. Muracciole, S. Moreau, Y. El Kaïm and A. Chrysochoos (2006) Thermo-kinematical analysis of rubber-like coupling effects in necked polyamide samples. Proceedings of Photomechanics'2006 conference, ClermontFerrand (France).

[19] T. Sentenac, Y. Le Maoult, G. Rolland and M.Devy (2003) Temperature Correction of Radiometric and Geometric Models for an Uncooled CCD Camera 
in the Near Infrared. IEEE Transactions on Instrumentation and Measurement $52(1): 46-60$.

[20] Y. Rotrou, T. Sentenac, Y. Le Maoult, P. Magnan and J. Farré (2005) Demonstration of near infrared thermography with silicon image sensors cameras. Proceedings of ThermoSense XXVII, Orlando, Florida (USA).

[21] Y. Rotrou, T. Sentenac, Y. Le Maoult, P. Magnan and J. Farré (2006) Near Infrared Thermography with Silicon FPA - Comparison to MWIR and LWIR Thermography. QIRT Journal, 3(1):93:115.

[22] Y. Rotrou (2006) Thermographie courtes longueurs d'onde avec des caméras silicium : contribution à la modélisation radiométrique. $\mathrm{PhD}$ thesis (in French), SUPAERO - École nationale supérieure de l'aéronautique et de l'espace (France).

[23] Jonathan M. Mooney and Freeman D. Shepherd (1996) Characterizing IR FPA nonuniformity and IR camera spatial noise. Infrared Physics \& Technology, $37: 595-606$.

[24] M. Schulz and L. Caldwell (1995) Nonuniformity correction and correctability of infrared focal plane arrays. Infrared Physics \& Technology, 36:763-777.

[25] Y. Shi, T. Zhang, Z. Cao and L. Hui (2005) A feasible approach for nonuniformity correction in IRFPA with nonlinear response. Infrared Physics \& Technology, 46:329-337.

[26] A. Ferrero, J. Campos-Acosta and A. Pons (2006) Non uniformity correction procedure for matrix detectors based on the prior compensation of its nonlinear behavior. Applied Optics, 45(11):2422-2427.

[27] G. Holst (1998) CCD Arrays Cameras and Displays. International Society for Optical Engineering, 2nd Edition. 
[28] K. Powell, C. Deeph, D. Fish and C. Thompson (1999) Restoration and frequency analysis of smeared CCD images. Applied Optics, 38(8):1343-1347.

[29] Wim Ruyten (1999) Smear correction for frame transfer charge-coupled-device cameras. Optics Letters, 24(13):878-880.

[30] A-C. Legrand (2002) Thermographie multispectrale haute et basse température - Application au contrôle non destructif. PhD thesis (in French), Université de Bourgogne - Laboratoire Le2i.

[31] P. Saunders (1997) General interpolation equations for the calibration of radiation thermometers. Metrologia, 34:201-210.

[32] F. Meriaudeau, E. Renier and F. Truchetet (1996) Temperature imaging and image processing in the steel industry. Optical Engineering, 35(12):3470-3481.

[33] F. Meriaudeau (2007) Real time multispectral high temperature measurement: Application to control in industry. Image and Vision Computing, 25:1124-1133.

[34] O.D. Faugeras (1993) Three-Dimensional Computer Vision: A Geometric Viewpoint. The MIT Press.

[35] D. Garcia, J.-J. Orteu and M. Devy (2000) Accurate Calibration of a Stereovision Sensor: Comparison of Different Approaches. Vision, Modeling, and Visualization 2000, Saarbrücken (Germany).

[36] D. Garcia (2001) Mesure de formes et de champs de déplacements tridimensionnels par stéréo-corrélation d'images. $\mathrm{PhD}$ thesis (in French), Institut National Polytechnique de Toulouse (France).

[37] VIC-2D and VIC-3D, Correlated Solutions, Inc., www.correlatedsolutions.com

[38] J.J. Orteu, T. Cutard, D. Garcia, E. Cailleux and L. Robert (2007) Application of stereovision to the mechanical characterisation of ceramic refractories reinforced with metallic fibres. Strain, 43(2):96-108. 
[39] Z.L. Kahn-Jetter and T.C. Chu (1990) Three-dimensional displacement measurements using digital image correlation and photogrammic analysis. Experimental Mechanics, 30(1):10-16.

[40] P.F. Luo, Y.J. Chao, M.A. Sutton and W.H. Peters (1993) Accurate measurement of three-dimensional deformable and rigid bodies using computer vision. Experimental Mechanics, 33(2):123-132.

[41] M.A. Sutton, S.R. McNeill, J.D. Helm and Y.J. Chao (2000) Advances in Two-Dimensional and Three-Dimensional Computer Vision. P.K. Rastogi (Ed.): Photomechanics, Topics Applied Physics 77, 323-372.

[42] D. Garcia and J.-J. Orteu (2001) 3D Deformation Measurement using Stereocorrelation applied to Experimental Mechanics. Proceedings of 10th FIG International Symposium on Deformation Measurements, Orange, California (USA).

[43] D. Garcia, J.J. Orteu and L. Penazzi (2002) A Combined Temporal Tracking and Stereo-correlation Technique for Accurate Measurement of 3D Displacements: Application to Sheet Metal Forming. Journal of Materials Processing Technology 125-126:736-742.

[44] J.J. Orteu, D. Garcia, L. Robert and F. Bugarin (2006) A speckle-texture image generator. Proceedings of the Speckle'06 International Conference, Nîmes (France).

[45] D. Hernandez (2005) A concept to determine the true temperature of opaque material using a tricolor pyroreflectometer. Review of Scientific Instruments, 76(024904):1-7.

[46] N. Ranc, V. Pina, G. Sutter and S. Philippon (2004) Temperature Measurement by Visible Pyrometry: Orthogonal Cutting Application. Journal of Heat Transfer, 126:931-936. 
[47] R. Siegel and J.R. Howell (1992) Thermal radiation heat transfer. Taylor and Francis.

[48] J.S. Lyons, J. Liu and M.A. Sutton (1996) High-temperature deformation measurements using digital-image correlation. Experimental Mechanics $36(1): 64-70$. 